\title{
PRKCB Gene
}

National Cancer Institute

\section{Source}

National Cancer Institute. PRKCB Gene. NCI Thesaurus. Code C39597.

This gene is involved in diverse cell processes such as apoptosis, B cell activation and endothelial cell proliferation. 